\title{
Implementation of Problem Solving With Concept Map to Improve Critical Thinking Skills and Chemistry Learning Achievement
}

\author{
Budi Utami ${ }^{1}$, Sulistyo Saputro ${ }^{1}$, Ashadi ${ }^{1}$, Mohammad Masykuri ${ }^{1}$, Alimin Sutanto ${ }^{2}$ \\ ${ }^{1}$ Postgraduate Program of Science Education Sebelas Maret University, Indonesia \\ ${ }^{2}$ Senior High School (SMA Negeri 2 Karanganyar), Indonesia \\ e-mail: budiutami@staff.uns.ac.id
}

\begin{abstract}
This study aims to improve: (1) student achievement on chemical equilibrium material through the implementation of Problem Solving learning model with concept map, (2) students' critical thinking skills on chemical equilibrium with Problem Solving and concept map. This research is an Action Research which is conducted in two cycles. Each cycle consists of four stages: planning, action, collecting data, and reflection. The subjects of the study were students of X IPA 1 at Senior High School in Karanganyar at 2016/2017 which has been using Curriculum 2013. Data collection research was using test techniques for cognitive domain and critical thinking skills, and non-test questionnaire for affective domain, observation sheet for affective domain. Data analysis was using descriptive analysis. The results showed that the implementation of Problem Solving with concept map can improve learning achievement and students' critical thinking skills. Improvement of learning achievement can be seen from the result of cognitive and affective domains. The percentage of cognitive domains in cycles 1 and 2 are $42.5 \%$ and $88.5 \%$. The result of affective domains on cycle 1 is very good $11 \%$, Good $87 \%$ and less $2 \%$, on cycle 2 very good $26 \%$ and good $74 \%$. For the improvement of students' critical thinking skills in Cycle I, and Cycle II, they are $65 \%$ and $84 \%$.
\end{abstract}

Keywords: Problem Solving, learning achievement, concept map, critical thinking skills

\section{INTRODUCTION}

Learning chemistry requires intelligent understanding and discernment because the chemistry is full of abstract concepts [1]. Chemistry is studied from three levels, namely sub-microscopic, macroscopic and symbolic and the relationship between these levels should be taught explicitly [2]. In addition, the interactions and differences between the three are important characteristics in Chemistry and are necessary to understand the concept. Therefore, the difficulties encountered by students at some level will affect the other levels. Students will find it difficult to study the characteristics of concepts in chemistry along with the concepts being represented (macroscopic, microscopic or symbolic) [3;4]. The methods students learn are potentially at odds with the nature of science that is the effect of the traditional methods used by teachers [5]. Chemistry is a discipline that studies 
macroscopic and microscopic material, the interaction between material and production and the use of materials [6]. Many students were showing misunderstanding in all areas of content in chemical equilibrium. Many students have misunderstandings in areas such as changing equilibrium conditions using the Le Chatelier Principle. According to student responses, misunderstandings arise through the use of rote learning, recall, algorithmic procedures, faulty control of the variables involved, limited use of chemical equilibrium laws, lack of mastery of chemical equilibrium principles and difficulties in transferring those principles to new situations [7].

Based on the observation, the teaching and learning activities of the students at grade 11th at one of senior high school in Karanganyar when the teacher gives the task to be done with the group, the students tend to be passive in doing the task given by the teacher, the students' ability to express the opinion is still lacking to solve the problem causing the students difficulties in developing the potential of critical thinking skills

Teachers still dominantly provide chemistry with lecture methods. Teachers in providing evaluation are still with cognitive problems at the level of knowledge, understanding and application (questions to measure low-level thinking skills). In the study of chemical equilibrium obtained an average daily test value of 56.47. Competence mastery limit is 75 . Students are still having difficulty in solving chemical equilibrium questions given by teachers. Students are still having difficulty in solving problems at the level of analysis, synthesis and evaluation. Researchers have found that often teachers ask significantly the cognitive question of lower level questions to a higher level. Questions should be designed to promote the facts and concepts of evaluation and synthesis [8]. Based on the research [9] it is known that teachers in the process of learning to teach chemistry in the class still find difficulty in applying the assessment on cognitive level of analysis, synthesis and evaluation. This causes the students are not familiar with the skills of critical thinking in solving high-order thinking problems. It is also known that students' critical thinking skills in grade 10th, grade $11^{\text {th }}$, grade 12 th have adequate critical thinking skills [9].

In a student centered learning process, students have the opportunity and facilities to build their own knowledge, so that they will gain a deep understanding and ultimately improve the quality of student learning outcomes. This can be realized if during the school has applied innovative learning model that will support students to play an active role and instill in students to think systematically and logically in overcoming the problems it faces. One way that can be taken to improve student achievement is by active learning through problem solving learning model. Model problem solving can be interpreted as a learning model that causes a lot of learning activities because students are faced with problems, formulate and test the truth to draw conclusions as the answer to the problem. Thus, through group discussion among students can be improved because students are triggered to solve problems or problems that exist by way of discussion and can motivate each other is expected to improve students' critical thinking skills. Application of this problem solving model, students become actively involved in exploring new situations, thinking of answering questions and solving realistic problems. The problem solving system in self learning strategy is called IDEAL, involving five stages: 1) Identify the problem. Learners must first know the problem before they can solve the problem. At this stage, learners ask themselves whether they have understood what the problem is and they 
can state the problem formulation clearly, 2) Define terms. Learners check whether they understand every word in the problem statement clearly, 3) Explore strategies. Learners gather relevant information and try a strategy to solve the problem. This may involve options such as drawing diagrams, 4) Act on the strategy. Once learners have explored various strategies, they now choose and use one strategy, 5) Look at the effects [10]. During this final stage, learners evaluate and analyze their investigations and the processes they use. With problem solving learning model can give a meaningful influence to improve critical thinking skill [11].

The use of learning models will be more appropriate and effective when equipped with learning media. The subject of chemical equilibrium is arranged hierarchically and coherently ranging from basic concepts to complex concepts, thus the concept hierarchy media is suitable for problem solving learning model. The concept hierarchy is the level of the most general concept to the most specialized concept. The concept hierarchy can be represented in the form of concept maps and is used to determine the sequence of conceptual learning, then the assessment of student skill aspects is assessed using concept maps because concept maps are the core basis of the taught material which affects the students' cognitive and perceptive thinking [12].

Some research shows that by studying in groups, discussing with friends in groups to solve problems, can improve students' critical thinking skills. Problem Solving can improve students' learning achievement in chemistry subjects. Research conducted by Festus and Ekpete concluded that Problem Solving learning makes students active, and can improve students' critical thinking skills in chemistry subjects [13].

The purpose of this study is to improve students' critical thinking skills and student learning outcomes on chemical equilibrium materials with problem solving learning model along with concept maps.

\section{METHOD}

This research used Action Research method conducted in two cycles, where each cycle consists of 4 stages: planning, implementation, data collection, and reflection. The subjects of the study were the students of class grade 11th at one of government senior high school in Karanganyar, Surakarta, Central Java at the academic year 2016/2017 with 38 students. Data sources are teachers and students. Data analysis in Action Research is done from the beginning until the end of data collection [14]. The data from the research result is processed and analyzed by a descriptive method. In this research used a triangulation technique to check the validity of data in research [14]. In this study the triangulation includes the results of discussion, concept maps and tests. The research data collection used the test technique for the learning achievement of knowledge and critical thinking skills, and non-test there are a questionnaire, observation sheet for activeness, and affective. 


\section{RESULT AND DISCUSSION}

\section{Cycle I}

\section{PLANNING}

At the planning stage a learning instrument and assessment instruments are developed. Preparing Learning Plan in cycle I was held 4 times face-to-face ie $6 \times 45$ minutes for delivery of materials and 2 x 45 minutes for cycle evaluation activities I.

\section{IMPLEMENTATION}

At the time of learning, learning activities are centered on students, teachers only as motivators and facilitators in learning. In learning the students are required to actively discuss and work together in groups to find solutions to the problem given.

In the early stages of learning to generate interest and curiosity of students, teachers give aperception and convey the purpose of learning in addition to it is also given motivation about the benefits of these materials to students.

The next step of the teacher's core activities to carry out the learning steps with problem solving method: 1) Identify the problem. Learners must first know the problem before they can solve the problem. At this stage, learners ask themselves whether they have understood what the problem is and they can clearly state the problem. At this stage students review issues from different perspectives, identify what is known and what is asked from the problem And examines the literature on average atomic mass and the concept of mole (observing). 2) Define terms. Learners check whether they understand every word in the problem statement clearly, Students are given the opportunity to ask questions about the material being studied (ask). 3) Explore strategies. Learners gather relevant information and try a strategy to solve the problem. Students work with each group to collect as much information as possible through various related sources to solve the given problem (collecting data). 4) Act on the strategy. After learners have explored various strategies, they now choose and use one strategy. Then the students discuss in groups to analyze the existing problems and write down the answers obtained (associate). Students are given the opportunity to communicate their discussion in front of the class (communicate) 5) Look at the effects. Evaluate and analyze the strategies that have been done to solve the problem.

The last stage, the teacher gives the best group, together with the students summarize the core concepts of the material that have been submitted as a form of reinforcement and the teacher gives the students a posttest problem. In the first cycle of learning I still have students who are less active in discussing with the group to solve the problem. In addition, there are still a few students who are active to ask questions and still need to be appointed if they want to present the results to the front of the class.

At the end of the first cycle, tests are conducted to determine students' cognitive, critical thinking skills and affective questionnaire. 


\section{COLLECTING DATA}

Collecting data is done simultaneously with learning in cycle I. At this stage teacher / researcher assisted by an observer to observe the process of learning process to assess student attitude.

\section{RESULTS OF CYCLE ACTION I}

Based on posttest result analysis of cognitive domains of cycle I obtained the result of cognitive domains in cycle I presented in Figure 1.

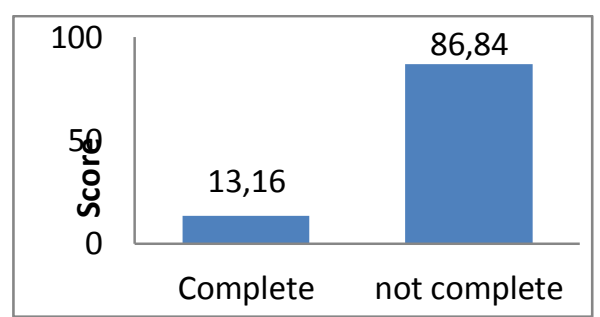

Figure 1. Completeness of Cognitive domains in Cycle I

The critical thinking skills obtained in cycle I are presented in Figure 2.

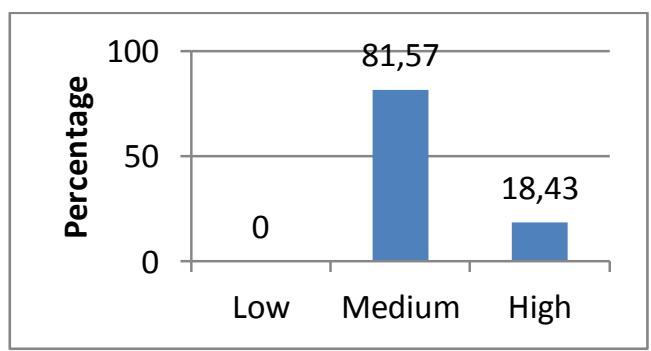

Figure 2. Critical Thinking Skills in Cycle I

The students' critical thinking skills are complete with indicators: 1) distinguishing facts, not facts and opinions, 2) distinguishing relevant and irrelevant information, 3) recognizing causation, 4) distinguishing definite and uncertain conclusions from observations or statements 5 ) Recognize cause and 6) consider another point of view. Student critical thinking skills of each component can be seen in Table 1. 
TABLE I. STUDENTS' CRITICAL THINKING SKILLS OF EACH COMPONENT

\begin{tabular}{|l|l|l|}
\hline \multicolumn{1}{|c|}{ Critical Thinking Components } & \multicolumn{1}{|c|}{$\begin{array}{c}\text { Critical Thinking } \\
\text { Indicators }\end{array}$} & $\begin{array}{l}\text { Level of students' } \\
\text { critical thinking skills }\end{array}$ \\
\hline $\begin{array}{l}\text { Differentiating the relevant and irrelevant } \\
\text { information }\end{array}$ & $\begin{array}{l}\text { Finding out the correct } \\
\text { reason based on the } \\
\text { statement }\end{array}$ & High \\
\hline $\begin{array}{l}\text { Differentiating between definitive and } \\
\text { temporary conclusion }\end{array}$ & $\begin{array}{l}\text { Drawing conclusion } \\
\text { based on the given } \\
\text { statements }\end{array}$ & Medium \\
\hline $\begin{array}{l}\text { Differentiating the fact, non fact and } \\
\text { opinion }\end{array}$ & $\begin{array}{l}\text { Choosing the statement } \\
\text { which is included in } \\
\text { opinion }\end{array}$ & Medium \\
\hline Making decision & $\begin{array}{l}\text { Making decision on the } \\
\text { situation that really needs } \\
\text { the problem solving }\end{array}$ & High \\
\hline Identifying cause and effect & $\begin{array}{l}\text { Determining the } \\
\text { relationship of related } \\
\text { cause and effect. }\end{array}$ & High \\
\hline Thinking critically based on what is read & $\begin{array}{l}\text { Drawing conclusion } \\
\text { based on the text }\end{array}$ & Medium \\
\hline Examining the level of trustworthiness & $\begin{array}{l}\text { Giving logical reason } \\
\text { related to the uncertainty } \\
\text { of information }\end{array}$ & Medium \\
\hline
\end{tabular}

From Table I it can be seen that students' critical thinking skills on the component differentiating the relevant and irrelevant information; making a decision and Identifying cause and effect are high. While on component differentiating between definitive and temporary conclusion; differentiating the fact, non-fact and opinion, thinking critically based on what is read; examining the level of trustworthiness is adequate. From interviews with students who cannot distinguish facts, non-facts and opinions. There are some students who cannot draw a conclusion based on the text and giving logical reason related to the uncertainty of information.

The result of observation on affective domains in cycle I can be seen in Figure 3.

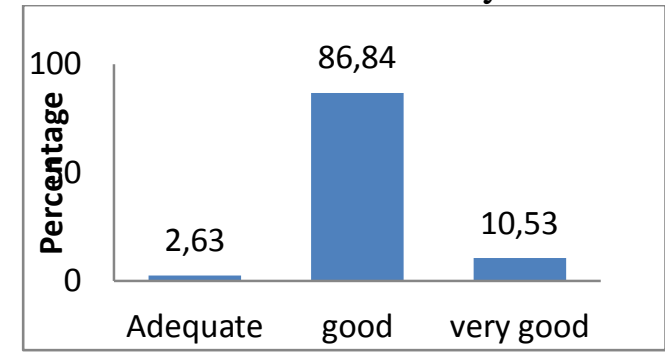

Figure 3. Observation of Students' affective domains in Cycle I

\section{REFLECTION}

From the results of cycle I that can be seen in Figure 1, there are still unfinished students. This is because there are still students who are less active in discussing with their group to solve the problem. In addition, there are still a few students who are active to ask questions and still need to be appointed if they want to present the results to the front of the class. The ability to think critically is not yet complete on 
indicators to test the reliability of a statement and think critically of what it reads. Therefore, it is necessary to carry out cycle II which is expected to increase.

\section{Cycle II}

\section{PLANNING}

In the second cycle of learning, the material was focused on competency indicators that have not been achieved in cycle I. In the learning process of this cycle II the number of group members was changed to smaller and upper group students divided equally in each group in the hope that students who are in the lower group can inquire about material that he has not understood with the students in the upper group.

\section{IMPLEMENTATION}

In the second cycle of learning, teachers encourage more students by motivating students to be more active in asking questions, responding to the group presenting the results in front of the class and more participate in group discussion activities.

In learning, students are more brave to ask the teacher or ask friends in a group more intelligent. Many students actively work in groups to solve problems. Many groups are keen to present the results of their discussions in front of the class. Students are also more enthusiastic to receive lessons so that more courageous expressed his opinion in front of the class. As other groups present the results in front of the class, many students are actively asking questions about the results of the discussions presented.

At the end of cycle II, tests are conducted to determine students' cognitive domains, critical thinking skills test and questionnaire.

\section{OBSERVATION}

The observations were conducted simultaneously with the implementation of cycle II actions. At this stage the teacher / researcher is assisted by the observer to observe the process of learning to assess the affective domains.

\section{RESULTS OF CYCLE ACTION II}

From the result of knowledge competency test of cycle II, the completeness of the cognitive domains of cycle II is presented in Figure 4.

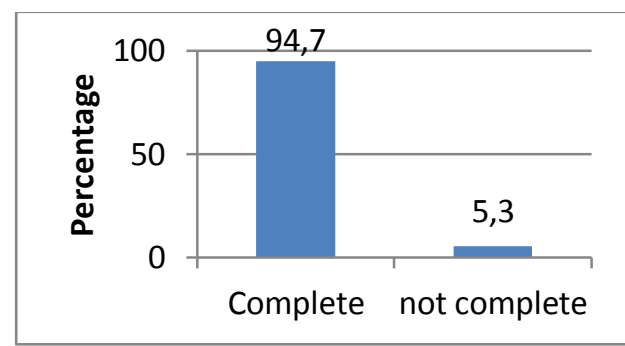

Figure 4. Results of cognitive domains of cycle II 
From the result of students' affective domains on cycle II can be seen in Figure 5.

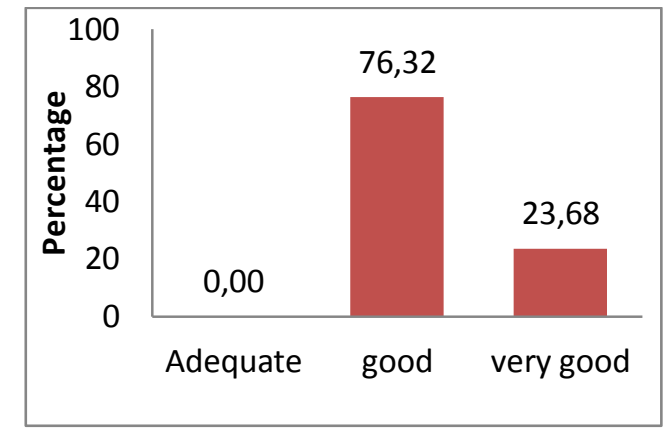

Figure 5. Results of affective domains of cycle II

From the results of critical thinking skills in cycle II can be seen in Figure 6.

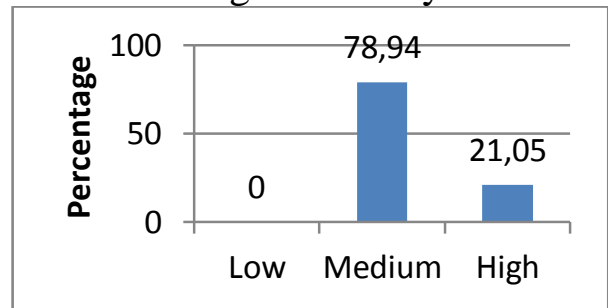

Figure 6. Critical thinking skills in cycle II

\section{Reflection}

From the results of cycle II that can be seen, that all aspects that include knowledge competence, attitudes and critical thinking skills have been completed. Therefore, it can be concluded that learning on chemical equilibrium materials with the learning model of Problem Solving learning along with concept maps have been successful.

From the result of concept mapping obtained average 86,14 it shows that the student has been able to make the concept map of chemical equilibrium well. Students can know the concepts and relationships between concepts in studying chemical equilibrium. With the concept map can be known changes in knowledge and understanding of students. Novak explains that learning is a change. Cognitive change is a set of unity that broadens memorization and meaningful learning. Meaningful learning can be achieved by 1) relevant initial knowledge, 2) meaningful material, that the knowledge learned must be relevant to other knowledge and must contain a significant concept. Students should choose meaningful learning. Students must be conscious and deliberate to connect new material with material that has been owned [12]. The studies illustrate how concept maps can be used to transform abstract knowledge and understanding into acceptable concrete visual representations for comparison and measurement. This article describes four important uses of the method: 1) identification of prior knowledge (and previous knowledge structures) among students; 2) presentation of new material in a way that facilitates meaningful learning; 3) division of knowledge and understanding experts among teachers and learners; 4) Documentation of knowledge changes to demonstrate integration of early knowledge of students and teaching [15]. 


\section{DISCUSSION}

Research data obtained include student achievement data consisting of cognitive, affective, as well as data from students' critical thinking skill test. For data cognitive domain is obtained from the evaluation test in the form of multiple choice questions of chemical equilibrium material, affective domain is obtained from questionnaires and questions to know critical thinking skills. Research conducted by Fatoke (2013) shows that the model of Problem Solving learning is more effective than the conventional learning model [16]. In addition, Problem Solving can also improve students' learning achievement in chemistry subjects. With the Problem Solving learning model encourages students to define problem-solving methods, to pursue and assess problem solving and to seek the feedback they need to complete their work and motivate them to learn forward [17]. Research confirms that Problem Solving learning can improve critical thinking skills by comparison of control classes that use learning without Problem Solving [18].

\section{CONCLUSION}

Problem solving learning model along with concept maps can improve students' critical thinking skills and student learning outcomes on chemical equilibrium materials. Improvement of learning achievement can be seen from the result of cognitive and affective domains. The percentage of cognitive domains in cycles 1 and 2 are $42.5 \%$ and $88.5 \%$. The result of affective domains on cycle 1 are very good $11 \%$, Good $87 \%$ and less good $2 \%$, on cycle 2 very good $26 \%$ and good $74 \%$. For the improvement of students' critical thinking skills in Cycle I, and Cycle II, they are $65 \%$ and $84 \%$.

\section{REFERENCES}

[1] M. Nakhleh, "Why Some Students Don’t Learn Chemistry Chemical Misconceptions," pp. 191-196.

[2] A. H. Johnstone, "seldom what they seem," pp. 75-83, 1991.

[3] A. H. Johnstone, "New Stars for the Teacher to Steer by ?," vol. 61, no. 10, pp. 847-849, 1984.

[4] G. Sirhan, "Learning Difficulties in Chemistry: An Overview," vol. 4, no. 2, pp. 2-20, 2007.

[5] A. H. Johnstone, "Nyholm Lecture: Chemical education research: Facts, findings and consequences Chemical Education Research : i," no. July, pp. 1-5, 2016.

[6] J. K. Gilbert and D. Treagust, "Models and Modeling in Science Education," vol. 9, 2016.

[7] K. M. . Mohideen, J.M; Karunaratne, S; Wimalasiri, "Proceedings of the Peradeniya University Research Sessions, Sri Lanka, Vol. 16, 24,” vol. 16, no. November, p. 2011, 2011.

[8] S. E. Walker, "Active Learning Strategies to Promote Critical Thinking," vol. 38, no. 3, pp. 263-267, 2003.

[9] B. Utami, S. Saputro, Ashadi, M. Masykuri, and S. Widoretno, "Critical thinking skills profile of high school students in learning chemistry," Int. J. Sci. Appl. Sci. Conf. Ser., vol. 1, no. 2, pp. 124-130, 2017.

[10] J. D. Bransford and B. S. Stein, The ideal problem solver: a guide for improving thinking, learning, 2nd ed. United States of America: W. H. Freeman and Company, 1993.

[11] A. Azaditablab and A. Veyseh, "Effect of Teaching Based on Group Problem Solving on Critical Thinking in Boy Students in Primary School in the City of Ilam," vol. 2015, no. 1, pp. 94-99, 2015.

[12] J. D. Novak, "A theory of education:," vol. 1, no. 2, pp. 1-14, 2011. 
[13] O. A. Ekpete, "Improving Students ' Performance and Attitude towards Chemistry through Problem-Based-Solving Techniques," vol. 1, no. 1, pp. 167-174, 2012.

[14] R. Sagor, The Action G Research Guidebook: A four-step process for educators and school teams. New Delhi: A Sage Publication Company, 2005.

[15] D. Hay, I. Kinchin, and S. Lygo-baker, "Making learning visible: the role of concept mapping in higher education," vol. 33, no. 3, pp. 295-311, 2008.

[16] A. O. Fatoke, T. O. Ogunlade, and V. . Ibidiran, "The Effects of Problem-Solving Instructional Strategy and Numerical Ability on Students' Learning Outcomes," Int. J. Eng. Sci., vol. 2, no. 10, pp. 97-102, 2013.

[17] C. Carvalho, E. Fíuza, J. Conboy, J. Fonseca, A. P. Gama, and M. H. Salema, "Critical Thinking, Real Life Problems and Feedback in the Sciences Classroom," vol. 12, no. 2, pp. 21-31, 2015.

[18] K. Y. Yin, “Collaborative Problem Solving Methods towards Critical Thinking," vol. 4, no. 2 , pp. 58-62, 2011. 